\title{
Relationships between practice, motivation and examination outcomes
}

\author{
Susan Hallam, University College London Institute of Education, UK \\ Ioulia Papageorgi, University of Nicosia, Cyprus \\ Maria Varvarigou, Canterbury Christchurch University, UK \\ Andrea Creech, Laval University, Canada
}

\begin{abstract}
While there has been a great deal of research on instrumental practice and the nature of motivation to engage with music making, there has been relatively little which has considered the relationship of these with instrumental examination outcomes. This research aimed to address this issue. 2131 young musicians, aged 6-19, across a wide range of expertise (from Grade 1 to higher education conservatoire entry level), with a range of examination outcomes from fail to highly commended, playing a wide range of instruments responded to a series of statements on a 7 point Likert scale relating to practice and motivation. Those merely awarded a pass grade in their examinations tended to undertake the least practice. Factor analysis revealed seven factors relating to practice and six to motivation. Multivariate analysis of variance showed that there were statistically significant differences between those with different examination outcomes in relation to the organisation of practice, the use of recordings and the metronome, the adoption of analytic strategies, social life and self-belief in musical ability. Students who received merely a pass grade in their examination responded least positively to these statements. Those who had failed were most likely to adopt ineffective practice strategies and were less likely to enjoy performing, playing, lessons and
\end{abstract}


practice. The findings are discussed in relation to earlier research and in terms of their educational implications.

\section{Keywords}

Education, Examination outcomes, Instruments, Motivation, Practice

\section{Introduction}

The aim of the research reported here was to consider the relationships between the quantity and quality of practice, motivation and the outcomes of graded instrumental music examinations. While there has been a great deal of research considering time spent practising, practice strategies and student motivation much of this has not been linked directly with instrumental examination outcomes. This paper will address that issue.

The level and quality of expertise attained in playing an instrument has largely been studied within the expertise paradigm, which suggests that the amount of time spent practising is the single strongest determinant of both (Ericsson et al., 1993). This has been challenged. While the length of time playing an instrument makes a major contribution to the level of expertise attained it is not the only factor, the quality of the practice undertaken is also important (for a review see Jørgensen and Hallam, 2016). Research on the quality of learning outcomes (in graded examinations, the mark attained), has not found strong consistent relationships between the amount of practice and the quality of performance (Williamon and Valentine, 2000; Hallam, 1998; 2013; Hallam, Rinta, Varvarigou, et al., 2012). Gruson (1988) and Hallam (1997, 2001a, 2001b) demonstrated how the quality of practice changes as instrumental skills develop. This includes having relevant schemata for what is to be learned; identifying and correcting errors; knowing what to do to improve; and how to organise and manage practice, motivation and behaviour, in other words having a range of metacognitive strategies. These processes have been conceptualised as self-teaching (Jørgensen, 2004) and self-regulation (McPherson \& Zimmerman, 2002). 
Motivation to play and continue to play a musical instrument is complex. To take account of this, various models of musical motivation have been developed. These recognise the interactions which occur between environmental (cultural, institutional, familial and educational) and internal factors (cognition and affect) which serve to enhance or reduce motivation (Evans, McPherson \& Davidson, 2013; Hallam, 2002; 2009; 2016; Sichivitsa, 2007). The models recognise the importance of musical identity, having positive self-beliefs and appropriate goals and aims, being able to attribute success and failure in ways which will support ongoing motivation and having a supportive environment both at home and in the environment more broadly. Self-belief is particularly important. Those who give up playing tend to have lower expectations of success (Pitts et al., 2000; Chandler et al., 1988) and are less confident about future outcomes largely through disappointing earlier experiences where they have not been successful (StGeorge, 2010).

Some research has focused directly on the perceptions of graded instrumental examinations of students, parents and teachers. Davidson and Scutt (1999) found that some students simply aimed to pass the examination and gain recognition for what they had achieved. In contrast, some teachers based their professional reputations on their students' performances. This led teachers to support students' learning, but also created stress. In a similar study, Mitchell (2012) concluded that enjoying learning music and being supported by teachers and parents contributed to positive performance experiences. Students with the strongest negative reactions to evaluative performance situations had extremely negative interactions with their parents and teachers who they perceived were out of touch with their needs and aims. Some students perceived the exam syllabus as boring and resented having to devote significant amounts of time to learning it. Successful students tended to have high levels of self- 
discipline, were able to attend to detail and to perform with confidence. Others viewed their musical pursuits as a personal, private endeavour and did not wish to perform as they suffered from extreme performance anxiety. For successful students, previous positive experiences were reaffirmed by high marks and positive comments. For the less successful, motivation was affected negatively, learning became stressful and a source of shame. Despite this, some continued to engage with playing informally choosing their own repertoire. Positive evaluations of performance enabled students to develop a strong musical identity. Those who had negative experiences tended to have weaker musical identities. Overall, this qualitative research raised important issues relating to the impact of different outcomes when taking graded music examinations.

In a series of studies which have direct relevance to the current paper, McPherson and McCormick (2000, 2003, 2006) included measures of cognitive strategy use, practice regulation, practice time, grade level, informal practice, formal practice and self-efficacy to explore what contributed to examination success. The participants, children and adolescents, completed a questionnaire immediately before their examination identifying what they believed would influence the results, their practice prior to the exam and what they expected to achieve. The findings showed that students attributed success to effort rather than to ability although many also attributed examination results to nervousness and luck. The most important predictor of success was the student's self-efficacy. The research reported here aims to extend this research by comparing the responses of learners whose most recent examination outcome was failure, a pass mark, being commended or highly commended in relation to self-reports of the amount of practice undertaken, the adoption of effective practice strategies, and a range of factors relating to motivation including having high levels of selfbelief. The research questions were: 
what differences, if any, are there between those who have failed or succeeded at different levels (pass, commended, highly commended) in graded instrumental music examinations in relation to:

— the amount of practice undertaken;

— the quality of the practice undertaken;

- motivation.

\section{Method}

A self-report questionnaire was used to collect data from a large sample of learners. The questionnaire was devised based on previous research relating to practice, in particular the work of Gruson (1988), and Hallam (1997; 2001a, 2001b) and, in relation to motivation, the model developed by Hallam, 2002, 2009, 2016). The questionnaire had been piloted in a smaller scale study (Hallam, 2013) and further used in research on the development of practising strategies (Hallam et al., 2012) and changes in musical motivation as expertise developed (Hallam, Creech, Papageorgi, et al., 2016).

The questionnaire sought information about the level of expertise attained as assessed by the highest graded instrumental examination taken from grade 1 to Grade 8 and the level of performance in that examination (fail, pass, commended, highly commended). Participants were asked about the number of days they carried out practice each week and how long each practice session lasted. The questionnaire also included a range of statements relating to various elements of practice including the strategies adopted, the organisation of practice, the perception of and handling of errors made, and ease of concentration. Statements relating to motivation included the support of family and friends; enjoyment of performing; music as a social activity; enjoyment of practice; self-beliefs about musical ability; and social affirmation. Respondents were requested to respond to these on a seven-point Likert scale 
with seven indicating the strongest agreement, one the strongest disagreement. The actual statements are set out in Tables 4 and 6.

\section{The sample}

Data were collected from young people representing all of the classical and popular musical instruments in a variety of settings including two junior conservatoires, two Local Authority youth orchestras, two Local Authority Saturday music schools, a conservatoire for popular music and three state comprehensive schools. The children who participated were receiving tuition on their instruments individually or in small groups of no more than four children.

A total of 3325 children ranging in level of expertise from Preliminary grade through to Grade 8 level (minimum required for conservatoire entrance in the UK) completed questionnaires. All of the children were from England. Only those who had taken graded instrumental examinations could be included in the current analysis. This excluded all of those who were at the preliminary level. The age range was from 6 to 19 years. The researchers who administered the questionnaires were available to offer support to any child or young person who did not understand the questions or the way that the rating scale worked. The instruments that they played were representative of the classical and popular instruments played in England. Table 1 sets out the relationship between the instruments played and the level of expertise of the participants. The age of the participants was strongly but not perfectly related with their level of expertise $(r=.638, p=.0001)$.

Table 1: Instruments played by level of expertise

\begin{tabular}{lrrrrrrrr}
\hline Instrument & \multicolumn{8}{c}{ Level of expertise } \\
& Grade 1 & Grade 2 & Grade 3 & Grade 4 & Grade 5 & Grade 6 & Grade 7 & Grade 8 \\
Violin (587) & $10 \%$ & $10 \%$ & $12 \%$ & $10 \%$ & $19 \%$ & $14 \%$ & $9 \%$ & $12 \%$ \\
Piano (278) & $14 \%$ & $7 \%$ & $8 \%$ & $10 \%$ & $17 \%$ & $8 \%$ & $16 \%$ & $20 \%$ \\
Flute (269) & $18 \%$ & $11 \%$ & $10 \%$ & $12 \%$ & $18 \%$ & $14 \%$ & $9 \%$ & $9 \%$ \\
Clarinet (248) & $17 \%$ & $8 \%$ & $15 \%$ & $9 \%$ & $20 \%$ & $12 \%$ & $11 \%$ & $8 \%$ \\
\hline
\end{tabular}




\begin{tabular}{lrrrrrrrr}
\hline Cello (209) & $9 \%$ & $5 \%$ & $10 \%$ & $10 \%$ & $18 \%$ & $11 \%$ & $12 \%$ & $25 \%$ \\
Trumpet (151) & $8 \%$ & $9 \%$ & $6 \%$ & $14 \%$ & $25 \%$ & $10 \%$ & $12 \%$ & $15 \%$ \\
Guitar (91) & $22 \%$ & $15 \%$ & $13 \%$ & $6 \%$ & $30 \%$ & $9 \%$ & $2 \%$ & $2 \%$ \\
Voice (82) & $3 \%$ & $2 \%$ & $13 \%$ & $10 \%$ & $27 \%$ & $12 \%$ & $20 \%$ & $13 \%$ \\
Saxophone (75) & $11 \%$ & $11 \%$ & $14 \%$ & $6 \%$ & $20 \%$ & $11 \%$ & $5 \%$ & $23 \%$ \\
French Horn (67) & $4 \%$ & $1 \%$ & $12 \%$ & $11 \%$ & $25 \%$ & $20 \%$ & $13 \%$ & $13 \%$ \\
Viola (65) & $17 \%$ & $9 \%$ & $4 \%$ & $14 \%$ & $18 \%$ & $8 \%$ & $20 \%$ & $9 \%$ \\
Trombone (62) & $6 \%$ & $9 \%$ & $8 \%$ & $6 \%$ & $18 \%$ & $20 \%$ & $12 \%$ & $21 \%$ \\
Oboe (49) & $11 \%$ & $2 \%$ & $5 \%$ & $0 \%$ & $27 \%$ & $16 \%$ & $22 \%$ & $16 \%$ \\
Drums (45) & $9 \%$ & $9 \%$ & $31 \%$ & $12 \%$ & $16 \%$ & $9 \%$ & $3 \%$ & $9 \%$ \\
Double bass (43) & $7 \%$ & $9 \%$ & $9 \%$ & $12 \%$ & $24 \%$ & $12 \%$ & $9 \%$ & $17 \%$ \\
Recorder (34) & $22 \%$ & $11 \%$ & $4 \%$ & $19 \%$ & $4 \%$ & $15 \%$ & $15 \%$ & $11 \%$ \\
Percussion (34) & $3 \%$ & $3 \%$ & $17 \%$ & $17 \%$ & $17 \%$ & $11 \%$ & $0 \%$ & $31 \%$ \\
Cornet (32) & $15 \%$ & $3 \%$ & $6 \%$ & $15 \%$ & $41 \%$ & $9 \%$ & $12 \%$ & $0 \%$ \\
Tuba (29) & $6 \%$ & $0 \%$ & $3 \%$ & $13 \%$ & $42 \%$ & $13 \%$ & $10 \%$ & $13 \%$ \\
Bassoon (22) & $4 \%$ & $16 \%$ & $8 \%$ & $8 \%$ & $24 \%$ & $12 \%$ & $12 \%$ & $16 \%$ \\
Harp (22) & $18 \%$ & $0 \%$ & $9 \%$ & $18 \%$ & $23 \%$ & $4 \%$ & $9 \%$ & $18 \%$ \\
\hline
\end{tabular}

Percentages have been rounded to the nearest full number. Percentages may therefore not sum to 100 Numbers in brackets indicate the total sample for that instrument

Overall, 230 participants reported having failed their most recent examination, 419 had passed, 818 had been commended and 664 were highly commended, a total of 2131 . There were no statistically significant gender differences in the percentage of students who failed, passed, or gained a commendation or a highly commendation outcome. There were statistically significant differences between instruments $\left(\chi^{2}=339.1, \mathrm{p}=.0001\right)$. Table 2 sets out the details. The numbers playing some instruments were very small. Where there were fewer than 20 playing an instrument, the data have been omitted from the table. The highest percentage of failures was in guitar (65\%). Other instruments with large percentages of failures were drums (47\%) and cornet (47\%). The smallest percentage of failures was for the viola $(6 \%)$. The instrument with the greatest number of highly commended passes was the recorder (50\%) followed by the bassoon (41\%) and voice (37\%). 
Table 2: Level of examination outcome by instrument in percentages

\begin{tabular}{lrrrr}
\hline & \multicolumn{1}{l}{ Fail } & Pass & Commendation & \multicolumn{2}{c}{ Highly } \\
& & & & commended \\
Violin (587) & $18 \%$ & $19 \%$ & $36 \%$ & $28 \%$ \\
Piano (278) & $28 \%$ & $14 \%$ & $26 \%$ & $31 \%$ \\
Flute (269) & $27 \%$ & $22 \%$ & $30 \%$ & $22 \%$ \\
Clarinet (248) & $23 \%$ & $21 \%$ & $38 \%$ & $19 \%$ \\
Cello (209) & $16 \%$ & $15 \%$ & $34 \%$ & $34 \%$ \\
Trumpet (151) & $11 \%$ & $23 \%$ & $40 \%$ & $26 \%$ \\
Guitar (91) & $65 \%$ & $8 \%$ & $18 \%$ & $10 \%$ \\
Voice (82) & $39 \%$ & $7 \%$ & $17 \%$ & $37 \%$ \\
Saxophone (75) & $31 \%$ & $24 \%$ & $27 \%$ & $19 \%$ \\
French horn (67) & $21 \%$ & $13 \%$ & $40 \%$ & $25 \%$ \\
Viola (65) & $6 \%$ & $31 \%$ & $39 \%$ & $25 \%$ \\
Trombone (62) & $26 \%$ & $8 \%$ & $40 \%$ & $26 \%$ \\
Oboe (49) & $16 \%$ & $14 \%$ & $43 \%$ & $27 \%$ \\
Drums (45) & $47 \%$ & $11 \%$ & $22 \%$ & $20 \%$ \\
Double bass (43) & $14 \%$ & $16 \%$ & $37 \%$ & $33 \%$ \\
Recorder (34) & $24 \%$ & $12 \%$ & $15 \%$ & $50 \%$ \\
Percussion (34) & $27 \%$ & $15 \%$ & $24 \%$ & $35 \%$ \\
Cornet (32) & $47 \%$ & $6 \%$ & $44 \%$ & $3 \%$ \\
Tuba (29) & $17 \%$ & $7 \%$ & $48 \%$ & $28 \%$ \\
Bassoon (22) & $14 \%$ & $32 \%$ & $14 \%$ & $41 \%$ \\
Harp (22) & $14 \%$ & $5 \%$ & $50 \%$ & $32 \%$ \\
\hline & & & &
\end{tabular}

Percentages have been rounded to the nearest full number. Percentages may therefore not sum to 100 Numbers in brackets indicate the total sample for that instrument

The research was designed taking account of the ethical guidelines of the British Psychological Society and the British Educational Research Association and was approved by the ethics committee of University College London Institute of Education. Participation was on a voluntary basis. The young people were briefed about the purposes of the research and provided with written and verbal assurances relating to anonymity and data protection. The young people were offered the opportunity to complete a questionnaire and no participants were coerced in any way. They were assured that the data would remain confidential and that their parents and teachers would not have access to it. 


\section{Findings}

Analysis of the relationship between level of expertise and examination outcomes showed that there was considerable variability in the nature of the examination outcome and grade level (see Table 3). For this reason, the multivariate analyses of variance which were undertaken used level of expertise as a covariate.

Table 3: Level of expertise by examination outcome

\begin{tabular}{lllll}
\hline $\begin{array}{l}\text { Level of } \\
\text { expertise }\end{array}$ & Fail & Pass & Commended & $\begin{array}{l}\text { Highly } \\
\text { commended }\end{array}$ \\
Grade 1 (286) & $15 \%$ & $28 \%$ & $38 \%$ & $19 \%$ \\
Grade 2 (197) & $11 \%$ & $28 \%$ & $41 \%$ & $20 \%$ \\
Grade 3 (253) & $12 \%$ & $26 \%$ & $39 \%$ & $23 \%$ \\
Grade 4 (246) & $9 \%$ & $31 \%$ & $37 \%$ & $23 \%$ \\
Grade 5 (495) & $12 \%$ & $18 \%$ & $42 \%$ & $28 \%$ \\
Grade 6 (297) & $13 \%$ & $18 \%$ & $40 \%$ & $29 \%$ \\
Grade 7 (269) & $11 \%$ & $13 \%$ & $40 \%$ & 36. \\
Grade 8 (354) & $3 \%$ & $8 \%$ & $31 \%$ & $58 \%$ \\
\hline
\end{tabular}

Percentages have been rounded to the nearest whole number and may not sum to $100 \%$

\section{Amount of practice}

The overall mean for average weekly practice of those who had failed their most recent examination was 233 minutes $(\mathrm{SE}=14.9)$, for those who had passed 177 minutes $(\mathrm{SE}=$ 11.1), for those with commendation 218 minutes $(\mathrm{SE}=7.6)$ and for those who were highly commended 308 minutes $(\mathrm{SE}=8.9)$. A multivariate analysis was undertaken and was statistically significant $(\mathrm{F}(1,3)=31.8, \mathrm{p}=.0001)$. At every grade level apart from grade 1 it was those who had only passed their last examination who did the least practice not those who had failed the exam. At Grade 1, those failing their examination did the least practice.

\section{Factor analysis of practice variables}

To explore associations between students' approaches to different aspects of practice, factor analysis was undertaken on the practice variables. A Principal components analysis was selected as it affords an empirical analysis of the data set (Tabachnick and Fidell, 2001).. A 
varimax rotation was used to enable interpretation and description of results (Tabachnick and Fidell, 2001). Two checks were made to assess sampling adequacy, the Kaiser-Meyer-Olkin (KMO) test (checks whether the sample is large enough to carry out factor analysis) and an anti-matrix of covariances and correlations which showed that all elements on the diagonal of these matrices were greater than -.5 , the necessary requirement. The $\mathrm{KMO}$ was 0.86 , greater than the 0.5 required to assess the adequacy of the sample (Field, 2009).

Decisions about the numbers of factors to be retained in any exploratory factor analysis depend on a range of criteria (Abell, Springer and Kamata, 2009). The Kaiser criterion suggests that eigenvalues above 1 should determine the number of factors (Guttman, 1954; Kaiser, 1960). However, Jollife $(1972,1986)$ suggests retaining factors with eigenvalues of more than 0.7. Sample size is also important. Stevens (2002) suggests that for samples of over 1000 factor loadings are significant if they exceed 0.162 . The number of factors can also be decided in relation to a scree plot (Cattell, 1966) or a subjective judgement either a priori or post hoc (Abell et al., 2009). A further consideration is that greater variance can be explained when a greater number of factors are included (Tabachnick and Fidell, 2001). As Abell et al. (2009) argue 'there is no magic formula to determine the correct number of latent factors' (p144). Taking this into account, eigenvalues were retained if they were greater than 1 and a scree plot was used to identify those factors before the breaking point of the elbow of the plot. Following examination of the scree plot a seven factor solution seemed to be the most appropriate. As the number of components with eigenvalues greater than 1 is usually somewhere between the number of variables divided by three and five, between nine and five factors might have been expected (Tabachnick \& Fidell, 2001). This supported a seven factor solution. Together the 7 factors accounted for $51 \%$ of the variance. Table 4 sets out the weightings for each variable. Weightings below 0.2 are not included. 
Factor 1, the adoption of systematic practice strategies, had high weightings for statements relating to practising things slowly (.65); knowing when a mistake was made (.56); practising sections slowly when a mistake was made (.73); repetition when something was difficult (.68); and playing passages slowly to start with then speeding up (.59). Factor 2, the organisation of practice, had high weightings for making a list of what to practice (.62); starting practice with scales (.73); starting with warm up exercises (56); and starting practice with studies (.49). Factor 3, using recordings and the metronome had high weightings for getting a recording of the piece to be learned (.67); recording practice and listening to the tapes (.74); and practising with a metronome (.64). Factor 4, the adoption of analytic strategies, had high weightings for getting an overall idea of a piece before practising it (.66); trying to find out what a piece sounds like before playing it (.76); working out where the difficult sections are (.52); and analysing the structure of a piece before learning to play it (.43). Factor 5, the adoption of ineffective practice strategies, had high weightings for only playing pieces from beginning to end without stopping (.7); when making a mistake going back to the beginning of the piece and starting again (.64); and a negative weighting for practising small sections (-.41). Factor 6 focusing on concentration had a high weighting for finding it easy to concentrate (.69) and a negative weighting for being easily distracted when practising (-.77). Factor 7 relating to the immediate correction of errors had high weightings for when making a mistake, stopping, correcting the wrong note and then carrying on (.71); and a negative weighting for when making a mistake carrying on with correcting it (-.79). Table 4 provides the details. The table is organised in relation to the factor structure. A few items had similar weightings across several factors. These were allocated to the conceptually most relevant factor. When a scale relating to practice is developed these will be removed. 
Table 4: Rotated component matrix for statements related to practice

\begin{tabular}{|c|c|c|c|c|c|c|c|}
\hline \multicolumn{8}{|c|}{ Rotated component matrix } \\
\hline & $\begin{array}{l}\text { Factor 1: } \\
\text { The } \\
\text { adoption of } \\
\text { systematic } \\
\text { practice } \\
\text { strategies }\end{array}$ & $\begin{array}{l}\text { Factor 2: } \\
\text { The } \\
\text { organisation } \\
\text { of practice }\end{array}$ & $\begin{array}{l}\text { Factor 3: } \\
\text { Using } \\
\text { recordings } \\
\text { and the } \\
\text { metronome }\end{array}$ & $\begin{array}{l}\text { Factor 4: } \\
\text { The adoption } \\
\text { of analytic } \\
\text { strategies }\end{array}$ & $\begin{array}{l}\text { Factor 5: } \\
\text { The } \\
\text { adoption of } \\
\text { ineffective } \\
\text { strategies }\end{array}$ & $\begin{array}{l}\text { Factor 6: } \\
\text { Concentration }\end{array}$ & $\begin{array}{l}\text { Factor 7: } \\
\text { The } \\
\text { immediate } \\
\text { correction } \\
\text { of errors }\end{array}$ \\
\hline \multicolumn{8}{|l|}{$\begin{array}{l}\text { The adoption of systematic practising } \\
\text { strategies }\end{array}$} \\
\hline I practise things slowly & .65 & & & & & & \\
\hline I know when I have made a mistake & .56 & & & & & .32 & \\
\hline $\begin{array}{l}\text { When I make a mistake I practise the section } \\
\text { where I went wrong slowly }\end{array}$ & .74 & & & & & & \\
\hline $\begin{array}{l}\text { When something is difficult I play it over } \\
\text { and over again }\end{array}$ & .68 & & & & & & \\
\hline $\begin{array}{l}\text { I learn by playing slowly to start with and } \\
\text { then gradually speeding up }\end{array}$ & .59 & .22 & & & & & \\
\hline $\begin{array}{l}\text { When I'm practising I mark things on the part } \\
\text { to help me }\end{array}$ & .31 & .30 & .23 & & -.31 & & \\
\hline \multicolumn{8}{|l|}{ The organisation of practice } \\
\hline I start my practice with scales & & .73 & & & & & \\
\hline $\begin{array}{l}\text { I set myself targets to achieve in each } \\
\text { practice session }\end{array}$ & .37 & .38 & .22 & & .21 & & \\
\hline I start my practice with studies & & .49 & .20 & & & & \\
\hline $\begin{array}{l}\text { I do warm up exercises at the start of my } \\
\text { practice }\end{array}$ & & .56 & .21 & & & .22 & \\
\hline I make a list of what I have to practise & & .62 & & & .21 & & \\
\hline \multicolumn{8}{|l|}{ Using recordings and the metronome } \\
\hline $\begin{array}{l}\text { I record myself playing and listen to the } \\
\text { tapes }\end{array}$ & & & .74 & & & & \\
\hline I practise with the metronome & & .22 & .64 & & & & \\
\hline $\begin{array}{l}\text { I try to get a recording of the piece that I am } \\
\text { learning so that I can listen to it }\end{array}$ & & & .67 & .25 & & & \\
\hline \multicolumn{8}{|l|}{ The adoption of analytic strategies } \\
\hline $\begin{array}{l}\text { I try to get an overall idea of a piece before I } \\
\text { practise it }\end{array}$ & & & & .66 & & .25 & \\
\hline $\begin{array}{l}\text { I work out where the difficult sections are } \\
\text { when I'm learning a piece of music }\end{array}$ & .29 & & & .52 & -.23 & & \\
\hline $\begin{array}{l}\text { I try to find out what a piece sounds like } \\
\text { before I begin to try to play it }\end{array}$ & & & & .76 & & & \\
\hline $\begin{array}{l}\text { I work things out just by looking at the music } \\
\text { and not playing }\end{array}$ & & & & .32 & .45 & & \\
\hline $\begin{array}{l}\text { I analyse the structure of a piece before I } \\
\text { learn to play it }\end{array}$ & & .40 & & .43 & .25 & & \\
\hline $\begin{array}{l}\text { I think about how I want to make the music } \\
\text { sound }\end{array}$ & .27 & .20 & .27 & .32 & -.27 & & -.22 \\
\hline \multicolumn{8}{|l|}{ The adoption of ineffective strategies } \\
\hline $\begin{array}{l}\text { When I practise I only play pieces from } \\
\text { beginning to end without stopping }\end{array}$ & & & & & .70 & & \\
\hline $\begin{array}{l}\text { When I make a mistake I go back to the } \\
\text { beginning of the piece and start again }\end{array}$ & & & & & .64 & -.25 & \\
\hline $\begin{array}{l}\text { I practise small sections of the pieces I am } \\
\text { learning }\end{array}$ & .40 & & & .26 & -.41 & & \\
\hline \multicolumn{8}{|l|}{ Concentration } \\
\hline I find it easy to concentrate when I practise & .26 & & & .23 & & .69 & \\
\hline I am easily distracted when I practise & & & & & & -.77 & \\
\hline \multicolumn{8}{|l|}{ The immediate correction of errors } \\
\hline $\begin{array}{l}\text { When I make a mistake, I stop, correct the } \\
\text { wrong note and then carry on }\end{array}$ & .23 & & & & & & .71 \\
\hline $\begin{array}{l}\text { When I make a mistake I carry on without } \\
\text { correcting it }\end{array}$ & & & & & & & -.79 \\
\hline
\end{tabular}


Where weightings are below 0.2 they have been omitted from the table

Multivariate analysis of variance of the seven factors by examination outcome with level of expertise as a covariate was statistically significant $(\mathrm{F}(21,5574)=5.7, \mathrm{p}=.0001)$. There were no statistically significant differences between those with different examination outcomes in relation to the adoption of systematic practice strategies, ease of concentration and immediate correction of errors. There were statistically significant differences in relation to the organisation of practice, the adoption of ineffective practice strategies, the use of recordings and the metronome and the adoption of analytic strategies. The students who had a pass grade in their last examination were those with the least positive responses not those who had failed, with the exception of the adoption of ineffective practice strategies (see Table $5)$.

Table 5: Differences in factor scores by examination outcome with level of expertise as

\section{a covariate}

\begin{tabular}{|c|c|c|c|c|c|c|c|c|c|}
\hline \multirow[b]{3}{*}{$\begin{array}{l}\text { Adoption of systematic practice } \\
\text { strategies }\end{array}$} & \multicolumn{2}{|l|}{ Fail } & \multicolumn{2}{|l|}{ Pass } & \multicolumn{2}{|c|}{ Commended } & \multicolumn{2}{|c|}{$\begin{array}{l}\text { Highly } \\
\text { commended }\end{array}$} & \multirow[t]{2}{*}{ SIG } \\
\hline & Mean & SD & Mean & SD & Mean & SD & Mean & SD & \\
\hline & -.04 & .93 & -.12 & .97 & .02 & .94 & .05 & .94 & NS \\
\hline Organisation of practice & .03 & .94 & -.09 & .95 & .01 & .94 & .15 & 1.0 & .0001 \\
\hline $\begin{array}{l}\text { Use of recordings and the } \\
\text { metronome }\end{array}$ & -.03 & .95 & -.14 & .92 & .02 & .99 & .36 & .97 & .0001 \\
\hline Adoption of analytic strategies & -.01 & .99 & -.08 & .92 & .09 & .95 & .05 & .94 & .007 \\
\hline $\begin{array}{l}\text { Adoption of ineffective practice } \\
\text { strategies }\end{array}$ & .04 & .92 & .03 & .93 & -.22 & .89 & -.44 & .91 & .0001 \\
\hline Ease of concentration & .01 & 1.0 & -.09 & .96 & -.01 & .94 & .09 & 1.0 & NS \\
\hline Immediate correction of errors & .02 & 1.1 & .005 & .97 & -.10 & .98 & .0003 & .94 & NS \\
\hline Support and social affirmation & -.01 & 1.0 & -.07 & .93 & .02 & .96 & -.06 & 1.0 & NS \\
\hline $\begin{array}{l}\text { Social life and enjoyment of musical } \\
\text { activities }\end{array}$ & .08 & 1.1 & -.09 & .98 & .14 & .92 & .17 & .94 & .039 \\
\hline Enjoyment of performing & -.13 & .99 & -.02 & .93 & .09 & .89 & .28 & .83 & .000 \\
\hline Self-belief in musical ability & -.01 & 1.0 & -.09 & 1.1 & -.05 & .92 & .21 & .92 & .000 \\
\hline $\begin{array}{l}\text { Enjoyment of playing, lessons and } \\
\text { practice }\end{array}$ & -.21 & 1.1 & .01 & .89 & .07 & .93 & .04 & .99 & .006 \\
\hline Disliking practice & .04 & .93 & .15 & .93 & .14 & .92 & .07 & 1.0 & NS \\
\hline
\end{tabular}




\section{Factor analysis of variables relating to motivation}

To explore associations between students' motivational beliefs, factor analysis was undertaken. The same principles were adopted as for the analysis of the practice data. Two checks were made to assess sampling adequacy, the Kaiser-Meyer-Olkin (KMO) test and an anti-matrix of covariances and correlations. This showed that all elements on the diagonal of these matrices were greater than -.5 , the necessary requirement. The KMO was 0.916 greater than the 0.5 required to assess the adequacy of the sample (Field, 2009). Taking into account the issues discussed in relation to the factor analysis of the practice variables, eigenvalues were retained if they were greater than 1. Following examination of the scree plot a 6 factor solution seemed to be the most appropriate. This was supported by the number of variables divided by 3 and 5 ( 9 and 5). Together the 6 factors accounted for $59 \%$ of the variance. Table 6 sets out the weightings for each variable. Weightings below 0.2 are not included. The statements are set out in the table in relation to the factor structure. In the few cases where there were similar weightings across different factors these have been located within the most conceptually relevant factor. They will be omitted from the future development of a measurement scale.

Six factors were identified. Factor 1, support and social affirmation had high weightings for parents wanting the participant to play an instrument (.74); relations liking them playing a musical instrument (.67); most people thinking that they played their instrument well (.64); teachers at school liking them to play a musical instrument (.49); and brothers and sisters liking them playing a musical instrument (.46). Factor 2, social life and enjoyment of musical activities had high weightings for having lots of friends who played musical instruments (.72); enjoying going to concerts to listen (.61); believing it was valuable to play a musical 
instrument (.59); playing an instrument being an important part of participants' social life (.54); and enjoying playing in musical groups, orchestras and bands (.44). Factor 3, enjoyment of performing had high weightings for statements relating to finding it very satisfying to play in concerts (.79); and playing in concerts giving participants a real thrill (.83). Factor 4, self-belief in musical ability had weightings for statements relating to needing musical ability to succeed in playing an instrument (.74); participants having musical ability (.64); having the potential to be a good musician (.56); usually being successful in what they attempted to do on their instrument (.49); and to a lesser extent being able to achieve anything that they wanted if they carried out sufficient practice (.37). Factor 5 , enjoyment of playing, lessons and practice had a high negative weighting for hating having to play an instrument (-.84) and a positive weighting for enjoying instrumental lessons (.72). Factor 6, disliking practice had high weightings for not wanting to practice on some days (.73), finding practice boring (.64) and a negative weighting for liking practice (-.66) (see Table 3 for further details). 
Table 6: Rotated component matrix for statements related to motivation

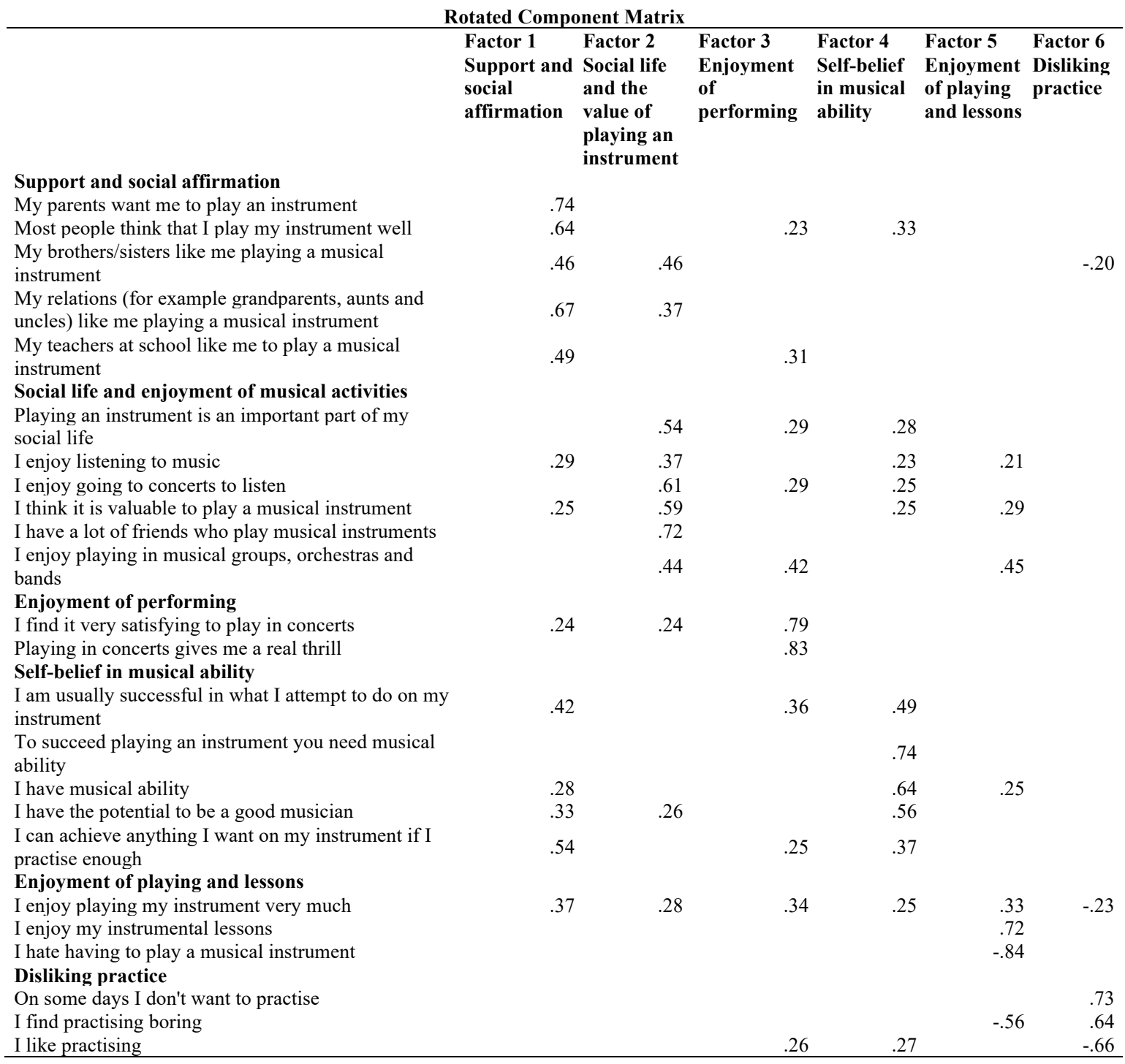

NB Weightings below 0.2 have been omitted from the table

A multivariate analysis of variance of the six factors by examination outcome with level of expertise as a covariate was statistically significant $(\mathrm{F}(6,1892)=4.35, \mathrm{p}=.0001)$.

There were no statistically significant differences in terms of examination outcomes with regard to support and social affirmation and disliking practice. There were statistically significant differences in relation to social life and enjoyment of musical activities and selfbelief in musical ability. The students who had a pass grade in their last examination were those with the least positive responses not those who had failed. Those who failed their 
examinations were less likely to enjoy performing, playing, lessons and practice (see Table $5)$.

\section{Practice and motivational factors as predictors of examination outcomes}

A multiple regression was undertaken which included all of the factors relating to practice and motivation with level of examination success as the dependent variable. Level of expertise was also included as there was variation in examination outcomes in relation to level of expertise. In total, there were 14 predictor variables an appropriate number given the size of the sample (Field, 2009). The Multiple $\mathrm{R}$ was $.32, \mathrm{R}^{2}=.18$ accounting for $18 \%$ of the variance. This was statistically significant $(F(14,1686)=13.94, p=.0001)$. Standardised beta coefficients were statistically significant for level of expertise (.11); enjoyment of performing (.10); self-belief in musical ability (.08); organisation of practice (.09); use of recordings and the metronome (.11); and the adoption of ineffective practice strategies (-.15). The contribution of each individual predictor to the regression model on examination outcomes can be seen in Table 7. 
Table 7: Predictors of examination outcomes

\begin{tabular}{|c|c|c|c|}
\hline & $\begin{array}{l}\text { Standardized } \\
\text { Beta } \\
\text { Coefficients }\end{array}$ & $\mathrm{t}$ & Sig. \\
\hline (Constant) & & 26.058 & .000 \\
\hline Level of expertise & .11 & 3.772 & .0001 \\
\hline Support and social affirmation & .03 & 1.301 & NS \\
\hline Social life and enjoyment of musical activities & .01 & .290 & NS \\
\hline Enjoyment of performing & .10 & 3.945 & .0001 \\
\hline Self-belief in musical ability & .08 & 3.076 & .002 \\
\hline Enjoyment of playing, lessons and practice & .03 & 1.247 & NS \\
\hline Disliking practice & .03 & 1.194 & NS \\
\hline Adoption of systematic practice strategies & -.02 & -.706 & NS \\
\hline Organisation of practice & .09 & 3.748 & .0001 \\
\hline Use of recordings and the metronome & .11 & 3.970 & .0001 \\
\hline Adoption of analytic strategies & .02 & .697 & NS \\
\hline Adoption of ineffective practice strategies & -.15 & -5.573 & .0001 \\
\hline Ease of concentration & .01 & .554 & NS \\
\hline Immediate correction of errors & -.01 & -.261 & NS \\
\hline
\end{tabular}

\section{Discussion}

There are limitations to this research based as it was on a self-report measure. This limitation applied to all participants. However, it is impossible to know with any certainty whether there was any bias between those responding who had failed, passed or been commended or highly commended. Some who had failed may have responded in ways that attributed their failure to external factors, while those with higher grades may have been biased towards internal attributions. The research was also limited in that it was not possible to more finely grade the examination outcomes as different examination boards were involved. This impacted on the extent to which fine grained prediction could be undertaken.

There were statistically significant differences in the percentage of learners gaining fail, pass, commended or highly commended examination outcomes between instruments and at 
different levels of expertise. There may have been several reasons for these differences. It is beyond the scope of this research to establish what these might be given that the research focus was the relationship between levels of examination outcomes, practice and motivation. However, there is clearly scope for further research exploring this issue.

Those examinees who were commended or highly commended reported the most positive and effective approaches to practice and the highest levels of motivation. The findings also revealed that for several of the factors it was those who had received a pass grade in the examination rather than those who had failed who gave the most negative responses. They reported doing less practice (apart from those having recently taken Grade 1), being less well organised in their practice, using recordings and the metronome less and that they were less likely to use analytic strategies. They indicated that music was a less important part of their social life. They also had lower beliefs in their musical ability. Overall, these findings suggest that these students had not developed a strong musical identity.

Why those who had received a pass grade in their most recent examination should have responded more negatively in these areas than those who had failed is counterintuitive. One possible explanation is that those who had failed were better supported by their teacher and significant others following failure. This may have enabled them to continue to be positive about playing a musical instrument. The need for such support when a participant had received a pass grade was perhaps not recognised. The role of parents and teachers in supporting musical learning has been extensively documented, for instance, Mitchell (2011) and Creech (2009). Mitchell found that some students were pressured by their parents and teachers to take examinations when they did not wish to do so. This may apply to some of the students in this study. Creech (2009) illustrated how the nature of the relationship between 
teacher, parent and pupil was crucial in determining learning outcomes. These relationships may be crucial in how students attribute their successes and failures and whether they are sufficiently resilient to continue playing following failure or gaining a pass grade.

Those who had failed their examination reported adopting ineffective practice strategies and that they were less likely to enjoy performing, playing, lessons and practice. Overall, this suggests that they were not strongly motivated in relation to their current musical activities which along with their reported ineffective practising strategies, contributed to their examination failure. Despite this, they had indicated that music was part of their social life. There are many possible explanations for this apparent contradiction. Perhaps those who failed their examination enjoyed making music with others as part of their social life but did not enjoy other aspects of learning to play an instrument including individual practice and their music lessons. Those playing guitar, drums and voice were among the instruments with the greatest percentage of failures. These are also the instruments most commonly associated with informal music making practices out of school allowing those students to have social ties to music without investing time in scholastic music pursuits. Although speculative, this reflects Mitchell's (2011) findings. Another possibility, also raised by Mitchell (2011), is that at least some of those who failed their examination may have experienced performance anxiety which they had not yet learned to control. The findings certainly showed that they did not enjoy performance. Even very young children can experience performance anxiety, although this improves the more experience that they have with performance (Boucher \& Ryan, 2011). Further research is needed to explore these issues.

None of the variables were very strong predictors of examination outcomes. The strongest were level of expertise, enjoyment of performing, self-belief in musical ability, organisation 
of practice, use of recordings and the metronome and in a negative direction the adoption of ineffective practising strategies. The students who were most successful in their examinations were those at the higher levels of expertise. Earlier research had already demonstrated significant linear trends as expertise developed in relation to enjoying performing, belief in musical ability (Hallam et al., 2016), the use of recordings and the metronome and decreasing use of ineffective practising strategies (Hallam et al., 2012). Taken together the findings suggest that there is a cycle where success in performance subsequently affects motivation to continue to learn, self-belief and commitment to improve learning strategies, while lack of success negatively affects motivation, self-belief and commitment to enhance learning processes. However, Mitchell (2011) suggests that the individual may still wish to be engaged with music but in a way which does not require anxiety provoking performances, perhaps through continuing to learn informally.

While self-belief contributed to explaining differences in examination outcomes, in contrast to the findings of McPherson and McCormick (2000, 2003, 2006), it was not the strongest predictor. There are a number of possible reasons for these differences in the research findings. The factors in the current research focused on specific aspects of practice. As the examinations did not include improvisation informal practice was not included. A number of motivational factors were included and self-efficacy was only one element of a factor focusing on self-beliefs relating to music more generally. Further research could explore the impact of the separate elements of the self-belief factor providing a better comparison with the findings of McPherson and McCormick. Perhaps the most important difference relates to the timing of the research. McPherson and McCormick assessed self-efficacy prior the participants taking their examination. At this point, feedback, particularly from teachers, is likely to have influenced their responses to statements about how confident they were about 
the examination outcome. The current research asked participants to indicate the outcome of their most recent examination, so the data on practice and motivation related to a time when the outcome of the examination was already known. In some cases, this may have been some time ago. Self-beliefs would therefore be based on current feedback from teachers and others which may have changed, positively or negatively, since the time of taking the examination.

\section{Educational implications}

The findings reported here indicate that it is not only failing an examination which may impact on motivation but also only gaining a pass mark. Teachers need to be aware of this and be ready to support students who may not have been as successful in examinations as they would like. The findings also indicate the importance of teachers modelling and discussing with their students how to practice effectively to maximise the time spent practising. Receiving constructive attributional feedback and helping students to focus on a range of strategies affecting performance including those related to practice, effort and coping with anxiety is clearly important when students have failed or not done as well as they had hoped in an examination.

\section{Acknowledgements}

We would like to acknowledge the contributions of Teresa Gomes, Tiija Rinta and Jennifer Lanipekun for their careful collection of the data contributing to the research.

\section{References}

Abell, N., Springer, D.W. \& Kamata, A. (2009). Developing and validating rapid assessment instruments. Oxford: Oxford University Press. 
Boucher, H., \& Ryan, C.A. (2011) Performance stress and the very young musician. Journal of Research in Music Education, 58(4), 329-345.

Cattell, R.B. (1966). The scree plot for the number of factors. Multivariate Behavioural Research, 1, 245-276.

Chandler, D., Chiarella, C., \& Auria, K. (1988). Performance expectancy, success, satisfaction, and attributions as variables in band challenges, Journal of Research in Music Education, 35(2), 249-258.

Creech, A. (2009). Teacher-parent-pupil trios: A typology of interpersonal interaction in the context of learning a musical instrument. Musicae Scientiae, XIII(2), 163-182.

Davidson, J. \& Scutt, S. (1999). Instrumental teaching with exams in mind: a case study investigating teacher, student and parent interactions before, during and after a music examination. British Journal of Music Education, 16 (1), 79-95.

Ericsson, K.A. , Krampe, R.T., \& Tesch-Romer, C. (1993). The role of deliberate practice in the acquisition of expert performance. Psychological Review, 100(3), 363-406.

Evans, P., McPherson, G.E. \& Davidson, J.W. (2013) The role of psychological needs in ceasing music and music learning activities. Psychology of Music, 41(5), 600-619.

Field, A. (2009). Discovering statistics using SPSS (Third Edition). Los Angeles: Sage publications. 
Gruson, L.M. (1988) Rehearsal skill and musical competence: Does practice make perfect? In J.A. Sloboda (Ed) Generative processes in music: The psychology of performance, improvisation and composition. Oxford: Clarendon Press.

Guttman, L. (1954). Some necessary conditions for common-factor analysis. Psychometrika, 19, 149-161.

Hallam, S. (1997) Approaches to Instrumental Music Practice of Experts and Novices: Implications for Education in Jorgensen, H., \& Lehman, A. (Eds) Does practice make perfect? Current theory and research on instrumental music practice. NMH-publikasjoner 1997:1, Oslo, Norway: Norges musikkh gskole. (pp 179- 231).

Hallam, S. (1998) Predictors of Achievement and Drop Out in Instrumental Tuition, Psychology of Music, 26(2), 116-132.

Hallam, S. (2001a) The development of expertise in young musicians: Strategy use, knowledge acquisition and individual diversity, Music Education Research, 3(1), 7-23.

Hallam, S. (2001b) The Development of Metacognition in Musicians: Implications for Education, The British Journal of Music Education, 18(1), 27-39.

Hallam, S. (2002). Musical Motivation: Towards a Model Synthesising the Research. Music Education Research, 4, 225-244. 
Hallam, S. (2009). Motivation to learn. In S. Hallam, I. Cross and M Thaut (eds) Handbook of Psychology of Music. (pp. 285- 294) Oxford: Oxford University Press.

Hallam, S. (2013) What predicts level of expertise attained, quality of performance an future musical aspirations in young instrumental players, Psychology of Music, 41(3), 267-291.

Hallam, S. (2016) Motivation to learn. In S. Hallam, I. Cross \& M Thaut (eds) Handbook of Psychology of Music (2 ${ }^{\text {nd }}$ edition). Oxford: Oxford University Press (pp. 285- 294).

Hallam, S. Creech, A., Papageorgi, I., Gomes, T., Rinta, T., Varvarigou, M. \& Lanipekun, J. (2016). Changes in motivation as expertise develops: Relationships with musical aspirations, Musicae Scientiae, 20(4), 528-550.

Hallam, S. Rinta, T. Varvarigou, M., Creech, A. Papageorgi, I., and Lani, J. (2012) The development of practising strategies in young people, Psychology of Music, 40(5), 652-680.

Jollife, L.T. (1972). Discarding variables in a principal component analysis, 1. Artificial data. Applied Statistics, 21, 160-173.

Jollife, L.T. (1986). Principal Component analysis. New York: Springer.

Jørgensen, H. (2004) Strategies for individual practice. In A. Williamon (Ed) Musical excellence (pp 85-104) Oxford: Oxford University Press. 
Jørgensen, H. \& Hallam, S. (2016) Practising In S. Hallam, I. Cross, I. \& M Thaut (eds) Oxford Handbook of Music Psychology (2 ${ }^{\text {nd }}$ edition) Oxford: Oxford University Press.

Kaiser, H.F. (1960). The application of electronic computers to factor analysis. Educational and Psychological Measurement, 20, 141-151.

McPherson, G.E. \& McCormick, J. (2000). The contribution of motivational factors to instrumental performance in a performance examination. Research Studies in Music Education, 15, 31-39.

McPherson, G.E. \& McCormick, J. (2003). The role of self-efficacy in a musical performance examination: An exploratory structural equation analysis, Psychology of Music, 31(1), 37-51.

McPherson, G.E. \& McCormick, J. (2006). Self-efficacy and performing music. Psychology of Music, 34, 322-336.

McPherson, G.E. \& Zimmerman, B.J. (2002) Self-regulation of musical learning. In R.Colwell \& C. Richardson (Eds) The new handbook of research on music teaching and learning (pp. 348-372) Oxford: Oxford University Press.

Mitchell, N. (2011) Evaluation in music study. Canadian Music Educator, Etibicoke, Ont., $53(1), 32-34$. 
Pitts, S. E., Davidson, J.W., \& McPherson, G.E. (2000b). Models of success and failure in instrumental learning: Case studies of young players in the first 20 months of learning. Bulletin of the Council for Research in Music Education, 146, 51-69.

Sichivitsa, V.O. (2007). The influences of parents, teachers, peers and other factors on students' motivation in music. Research Studies in Music Education, 29, 55-67.

Stevens, J.P. (2002). Applied Multivariate statistics for the social sciences (4 ${ }^{\text {th }}$ edition). Hillsdale, NJ: Erlbaum.

StGeorge, J. (2010). The subjectivity of musical learning: Understanding participation in instrumental music instruction. Unpublished PhD, University of Newcastle, New South Wales.

Tabachnick, B.G. \& Fidell, L.S. (2001). Using multivariate statistics (Fourth Edition). Boston: Allyn and Bacon, Pearson International.

Williamon, A. and Valentine, E. (2000). Quantity and quality of musical practice as predictors of performance quality. British Journal of Psychology, 91, 353-376. 